\title{
Metacognitive Confidence Can Increase but Also Decrease Performance in Academic Settings
}

\author{
Lorena Moreno $^{1}$ (D) Pablo Briñol ${ }^{1}$ (D) $\cdot$ Richard E. Petty ${ }^{2}$ (D)
}

Received: 24 September 2020 / Accepted: 17 July 2021 / Published online: 9 September 2021

(c) The Author(s) 2021, corrected publication 2022

\begin{abstract}
The present research examined the role of metacognitive confidence in understanding to what extent people's valenced thoughts guide their performance in academic settings. First, students were asked to engage in positive or negative thinking about exams in their major area of study (Study 1) or about themselves (Studies 2 and 3). The valence of these primary cognitions was manipulated to be positive or negative. Furthermore, a metacognitive variable, the perceived validity of the primary cognitions, was measured or varied to be relatively high or low. Finally, performance was assessed using a knowledge test (Study 1), a geometric shapes task (Study 2) or a selection of questions from the Graduate Record Examination (Study 3). In accordance with self-validation theory, we predicted and found that metacognitive confidence (relative to doubt) increased the impact of primary cognitions on performance. When thoughts were positive, increased confidence in the primary cognitions improved performance. However, when thoughts were negative, the same confidence validated the negative primary cognitions and reduced performance. Thus, metacognitive confidence can lead to opposite findings on performance depending on whether it validates performance-relevant positive thoughts or negative thoughts. Variations in the perceived validity of thoughts mediated the obtained effects. Therefore, we conclude that understanding the process of thought validation can help in specifying why and when metacognitive confidence is likely to work or to backfire in producing the desired performance effects.
\end{abstract}

Keywords Thoughts · Primary and secondary cognitions $\cdot$ Metacognition · Confidence Academic performance

Lorena Moreno

lorena.moreno@uam.es

Pablo Briñol

pablo.brinnol@uam.es

Richard E. Petty

petty.1@osu.edu

1 Department of Psychology, Universidad Autónoma de Madrid, Madrid, Spain

2 Department of Psychology, Ohio State University, Columbus, OH, USA 
Performance in academic settings is guided in part by accessible primary cognitions about oneself or the task at hand. These primary cognitions include thoughts and beliefs about one's skills (e.g., I can do this well; I am a good student) as well as the nature of the task (e.g., the test will be very difficult; this exam is useless), and many other relevant ideas. Such cognitions that pop into peoples' heads have the potential to impact performance. A relevant dimension of primary cognition that has been heavily studied in academic domains and beyond is the number or amount of performance-relevant thoughts. For example, Elliot et al. (1999) found that how much people thought about the test while taking it contributed to explaining the number of correct responses (Grass et al., 2017; Preckel et al., 2006; Strobel et al., 2019; von Stumm \& Ackerman, 2013).

Beyond the amount of thinking, another important dimension that influences performance is the direction or valence of primary cognitions. For example, participants who have positive performance-relevant thoughts (e.g., yes, I can; this test is well suited for me) are more likely to do well on a variety of academic tasks than those who have neutral or negative thoughts (e.g., Burgmer \& Englich, 2012; Gilman et al., 2006; Hertwig \& GrüneYanoff, 2017; Snyder et al., 2002; Taylor \& Walton, 2011). In one illustration, Martens et al. (2006) showed that women who were asked to generate positive thoughts about the self before taking a spatial rotation test and a math test performed better on those tasks than those asked to generate more neutral, control thoughts (see Miyake et al., 2010 for similar findings). Generating positive thoughts about oneself or the task has been associated not only with better performance at school but also with subsequent professional success and wellbeing (Lange et al., 1998; McGuire \& McGuire, 1996; Seligman, 2018; Taylor et al., 2003; Merlo et al., 2018).

While having positive thoughts is associated with desired outcomes, having negative thoughts (e.g., focusing on worries, self-handicapping, etc.) is often associated with reduced academic performance compared to neutral or positive thoughts (Caraway et al., 2003; Davis \& Nolen-Hoeksema, 2000; De Castella et al., 2013; DeCaro et al., 2010; Hunsley, 1985; von Hippel et al., 2019). For example, De Castella et al. (2013) classified students depending on the valence of their primary cognitions as measured with inventories such as success orientation and fear of failure. Higher levels of fear of failure were associated with less academic achievement and with more use of several maladaptive strategies such as self-handicapping behavior and school disengagement (Au et al., 2009; Martin, 2012).

The current research examines the role of a third, metacognitive, dimension of thinking - the perceived validity of one's thoughts (metacognitive confidence). As described in more detail shortly, the current research examines how perceived thought validity can interact with the valence of primary cognitions to determine performance in an academic context. Before getting to our core hypotheses and outline of the current research, we next elaborate upon the role of metacognitive confidence in educational settings.

\section{Metacognition}

Metacognition refers to the distinction between primary and secondary thoughts. Primary thoughts involve people's initial associations of some object with some attribute, or a projection of some object onto some dimension of judgment such as "I am a good student" (McGuire \& McGuire, 1996). These primary cognitions can be focused on oneself, other people, the environment, or at any object (e.g., exams). As noted, many thoughts 
can serve as primary cognitions, including beliefs about self, one's classroom, the teacher, and many other ideas, and cognitions. Critical to the current research is that following a primary thought or cognition, people can also generate other thoughts that occur at a secondary level which involve reflections on the first level thoughts (e.g., Am I confident that I am a good student?). Metacognition refers to these second order thoughts, or thoughts about one's primary cognitions or thought processes (Briñol \& DeMarree, 2012; Dunlosky \& Metcalfe, 2009; Goupil \& Kouider, 2019). In educational settings, metacognition is considered one of the most relevant predictors of performance (Metcalfe, 2009; Rawson \& Dunlosky, 2007; Veenman \& Alexander, 2011; Wang et al., 1990; see Hacker et al., 2009 , for a review). Previous research in this domain has mainly focused on two separate but related aspects of metacognition: metacognitive knowledge and metacognitive control (Hacker et al., 2009; Mayer \& Alexander, 2011).

Metacognitive knowledge refers to people's naïve theories about their knowledge. For example, Flavell et al. (1970) showed that how many hours students dedicated to studying depended on how much they thought they knew (subjective knowledge) regardless of how much they actually knew (objective knowledge; see Metcalfe, 2009, for additional examples). Also, the stronger one's feeling of knowing about a piece of information, the more time one is willing to spend searching for it (e.g., Costermans et al., 1992). The second aspect, metacognitive control, is also important for performance and refers to the regulation of cognitions to improve effectiveness (Brown, 1987; Hacker et al., 2000; Roebers et al., 2009; Schraw \& Dennison, 1994). In prior research, accuracy is the key feature emphasized regarding these metacognitive aspects (Koriat, 2019; Nietfeld et al., 2005; Stankov \& Lee, 2008; Stankov et al., 2012).

Instead of focusing on the relationship between metacognitive knowledge and control with accuracy as most prior research on metacognition does (e.g., Hacker et al., 2000; Koriat, 2011, 2019; Metcalfe, 2009; Nietfeld et al., 2005; Roebers et al., 2009; Stankov \& Lee, 2008), the present research focuses on a sense that one's thoughts are valid or appropriate to use in guiding performance regardless of accuracy. As we describe next, the perceived validity of primary cognitions is one of the most essential dimensions of metacognition that determines whether thoughts are translated into judgments and action. Indeed, metacognitive confidence can enhance, attenuate, or even reverse the impact of primary cognitions (Petty et al., 2007).

\section{Metacognitive Confidence}

Previous literature on metacognition focused on accuracy has typically measured metacognitive confidence by asking participants about correctness (e.g., Are you sure your answer is correct?) in domains in which there is an objectively correct response (Ais et al., 2016; Efklides, 2011; Finn, 2008; Fleming et al., 2010; Hacker et al., 2000; Koriat, 2011, 2019; Maclellan, 2013; Nietfeld et al., 2005; Stankov \& Lee, 2008; Stankov et al., 2012; for a review Brewer \& Sampaio, 2006; Fleming \& Daw, 2017; Fleming \& Lau, 2014; Pleskac \& Busemeyer, 2010). Instead of examining accuracy, the present research concerns people's confidence in their opinion-based thoughts, where there is no objectively correct answer. Specifically, we focus on subjective perceptions that one's thoughts are valid or appropriate to use in guiding performance. The key idea is that, although there is no actual accuracy, people still can feel that their thoughts (e.g., about their own strengths and weaknesses, or about exams, etc.) are the valid ones to use in guiding their performance. Therefore, in 
the present studies, metacognitive confidence is defined as a subjective belief regarding the validity of any primary cognition. Regardless of the accuracy of the initial belief, this subjective feeling of confidence about a thought is important because it can determine the extent to which people`s thoughts are used in forming judgments and, ultimately, in guiding their behavior.

Self-validation theory is a conceptualization that focuses on this essential aspect of metacognition: perceived thought validity. Unlike previous work on metacognitive accuracy, research on self-validation has shown that people's perceptions of their thought validity can stem from different antecedents, including a large list of incidental inductions such as recently recalling past instances of confidence (Petty et al., 2002) or having a momentary feeling of being powerful (Briñol et al., 2007; Durso et al., 2016). Also, people infer the validity of their thoughts based on the ease with which those thoughts come to mind. In self-validation studies, ease is manipulated to come from many different sources completely unrelated to the availability of information, including writing thoughts with a dominant hand (Briñol \& Petty, 2003) or increasing the contrast between font and background (Briñol et al., 2006). Therefore, this self-validation approach is similar to other metacognitive accounts in highlighting the importance of perceptions of thought validity but differs from other metacognitive approaches in identifying sources of thought validity independent of accuracy, availability, skills for signal detection, memory abilities, etc.

Research on self-validation has shown that, when being deliberative, the confidence that people have in their thoughts is a critical determinant of whether those thoughts lead to more moderate or extreme judgments and action. Most of the prior self-validation work has been focused on examining specific variables of social influence that could affect perceived thought validity (e.g., credible persuasive sources; Briñol \& Petty, 2009a) and domains within social psychology in which validation processes operate (e.g., attitude change; Briñol \& Petty, 2009b). The goal of the current research is to introduce self-validation as a useful approach that can extend the utility of metacognitive validation processes to the domain of performance in academic settings.

To illustrate the utility of the self-validation approach, consider one study in the domain of attitude change. In this research (Petty et al., 2002, Study 2), undergraduate students received a message on the topic of instituting comprehensive exams for seniors. The students were randomly assigned to generate either positive or negative thoughts about the proposal (primary cognitions) and then they rated the validity of each thought listed (metacognitive confidence). Finally, participants provided their attitudes toward the proposal. The predicted interaction between valence of thoughts and thought validity on attitudes toward the proposal emerged. This interaction showed that the valence of participants' thoughts had an increasingly larger impact on judgments as perceived thought validity increased. The same occurred when the validity of thoughts was manipulated (by asking participants to recall past instances of confidence vs. doubt) rather than measured (Petty et al., 2002, Experiment 3).

In another set of examples, consider the metacognitive confidence that comes from feelings of power following thinking. The confidence that comes from feeling powerful can magnify whatever mental content is accessible increasing and decreasing cooperation or competition (Decelles et al., 2012; DeMarree et al., 2014; Hirsh et al., 2011), and leading to action or inaction (Durso et al., 2016), depending on what the primary cognitions are to begin with (e.g., positive or negative thoughts; thoughts about cooperation or competition).

In a recent self-validation work illustrating how thought confidence can moderate the impact of self-relevant thoughts (or self-talk) on behavior (Horcajo et al., 2019), cross fit athletes were randomly assigned to generate either positive or negative statements about 
themselves. In this paradigm, self-talk (i.e., generating positive or negative thoughts about oneself) served as the primary cognition induction. This initial induction was based on extensive literature on sport performance showing that what athletes say to themselves prior to or during performance can influence their performance outcome (e.g., Hatzigeorgiadis et al., 2011; Tod et al., 2011; Van Raalte et al., 2016). After generating positive or negative thoughts, the athletes were randomly assigned to a thought validation induction (nodding or shaking their heads) while listening over headphones to the self-statements they had recorded. Specifically, nodding one's head in a vertical manner while thinking leads to higher perceived thought validity than shaking one's head in a horizontal manner while thinking (Briñol \& Petty, 2003). Finally, physical performance was assessed in tasks such as vertical jump. Consistent with the self-validation hypothesis, athletes' self-talk was significantly more impactful on their physical performance in the head nodding (validation) than in the head shaking (invalidation) condition. That is, when self-thoughts were positive, nodding led to better performance than shaking, but when self-thoughts were negative, the opposite resulted. In the present research, we examine for the first time to what extent metacognitive confidence (validity of thoughts) can also validate positive and negative thoughts affecting performance in an academic context.

\section{Overview}

The present research examines whether metacognitive confidence in performance-relevant thoughts can play a role in determining actual performance on academic tasks. All of our studies include a variable of performance-relevant primary cognition (i.e., positive or negative thoughts about exams or about the self) and a variable of secondary thinking (i.e., metacognition involving the perceived validity of thoughts). In the first study, validity of thoughts was simply measured by asking participants how confident they were in their thoughts, and in the second and third studies validity of thoughts was experimentally manipulated. Importantly, Study 3 included both a manipulation of thought validity and a subsequent assessment of that induction on perceived thought validity as the proposed mediator (i.e., a metacognitive assessment).

According to the self-validation hypothesis, we expected that the effect of the primary cognitions on performance would be greater for participants with higher levels of metacognitive confidence in their cognitions compared to those with relatively lower levels of thought confidence. Thus, we expected an interaction between thought valence and their perceived validity in predicting performance in academic settings. Thought valence would have a larger impact on performance under high rather than low metacognitive confidence conditions. Stated differently, higher confidence in positive thoughts would produce enhanced performance, but higher confidence in negative thoughts would produce diminished performance. This interaction pattern would extend prior work on self-validation to the domain of performance in academic settings.

\section{Study 1}

The primary goal of Study 1 was to provide an initial examination of our interaction hypothesis that metacognitive thought confidence would moderate the impact of primary cognitions on academic performance. To manipulate the valence of primary cognitions, 
undergraduates received information about a persuasive proposal advocating in favor of or against implementing senior comprehensive exams at their own university. Following this induction, participants reported the extent to which they had confidence in the thoughts they just listed. Finally, performance was measured with the scores obtained by the students in a brief exam about knowledge in the students' major - psychology.

\section{Method}

\section{Participants and Design}

One hundred and twenty-seven undergraduate psychology majors (115 females, 11 males, and 1 unidentified) participated anonymously in this study. The age of the participants ranged from 18 to $29\left(M_{\text {age }}=20, S D=1.61\right)$. Participants were randomly assigned to one of two thought valence (Positive vs. Negative) conditions and the perceived validity of those thoughts (metacognitive confidence) was an additional measured predictor variable. Exam performance was assessed as the dependent variable. A power analyses was conducted using $\mathrm{G}^{*}$ Power (Faul et al., 2007). After obtaining the effect in a pilot study briefly described in footnote 1 (i.e., Cohen's $f^{2}=.043$ ), we planned for a similar effect size in this study. ${ }^{1}$ The desired sample size for a two-tailed test $(\alpha=.05)$ of the predicted interaction with .80 power was a total of $N=186$ participants. Our final sample was determined based on the number of participants that could be collected during the week in which the study was posted, resulting in a relatively smaller number of participants (127 participants) compared to the estimated one. The final sample results in power of .64 to detect the anticipated effect size based on pilot study.

\section{Procedure}

Permission to conduct the study was provided by the university institutional ethics committee before the study began. Upon arrival, participants were led to believe that their university had recently begun to consider a new policy requiring seniors to pass comprehensive exams in their major areas to graduate (see Petty \& Cacioppo, 1986, for further details on this particular academic topic). Participants were told that if implemented, the exam policy

\footnotetext{
1 We conducted a pilot study in which primary and secondary cognitions were measured. Psychology undergraduate students were asked to complete the general self-efficacy scale (GSE, Schwarzer \& Jerusalem, 1995). General self-efficacy aims to assess a person's primary beliefs regarding a broad and stable sense of personal competence to deal effectively with a variety of demanding or novel situations, such as exams. Beliefs in one's self-efficacy can serve as primary cognitions and therefore be held with different levels of metacognitive validity. This approach matches with Bandura's view since he treated self-efficacy as primary beliefs about one's capability to produce outcomes (Bandura, 1977, 1986, 1989). In this pilot study, participants' reports of their own self-efficacy served as a proxy to classify the students according to the relative valence of their cognitions (relatively positive or negative in their perceived self-efficacy). Participants then reported their certainty in their responses to the self-efficacy scale. Finally, students were asked to complete a battery of tasks which included a geometric shapes task, syllogism problems, and a brief exam about knowledge in the students' major - psychology. Results showed that the extent to which participants saw their scores in self-efficacy as relatively high (vs. low) in validity influenced the impact of those primary cognitions (self-efficacy beliefs) on performance, $B=0.768$ (95\% CI: $0.150,1.385), t(140)=2.457, p=.015$, Cohen's $f^{2}=.043$.
} 
would begin in the next academic year and would apply to all students currently enrolled at their university. The topic was framed to be of high personal relevance to all participants (Petty \& Cacioppo, 1979; Tormala et al., 2002) because metacognitive processes of validation are more likely to occur when students are motivated to think. Then, the students were told that before implementing this exam policy, their university wanted to assess their reactions and so they would be asked to read about the policy and report their thoughts and opinions about it. After that, participants were randomly assigned to receive a persuasive message that presented either positive (i.e., benefits) or negative (i.e., problems) information about these comprehensive exams. Additionally, participants listed either positive or negative thoughts towards the exams to match the received message (primary cognitions). Next, participants indicated the perceived validity of the thoughts (metacognitive confidence) they generated about the exam proposal. Finally, participants' performance was assessed by asking them to do a brief psychology exam. After reporting demographic and ancillary questions, participants were thanked and debriefed.

\section{Predictor Variables}

\section{Thought Valence}

Participants were randomly assigned to generate either positive or negative thoughts about the exams (primary cognitions). As noted above, this manipulation was accomplished by first exposing the participants to a one-sided message in favor or against the exams and by asking them to generate thoughts only in the same direction as the message. The messages were taken from prior research (e.g., see Briñol et al., 2006; Tormala et al., 2007).

In the positive thoughts condition, the message emphasized various benefits of comprehensive exams. For example, the message said that "students and faculty would work harder. The prospect of a comprehensive exam would increase the grade point average of undergraduates significantly," as well as "students from institutions with comprehensive exams are more likely to be accepted into good graduate programs," and "in recent years, starting salaries of students from other institutions with comprehensive exams have been, on average, three thousand to four thousand dollars higher than starting salaries for students graduating from comparable institutions without the exams." Additionally, after reading this message presenting exclusively arguments in favor of the proposal, participants in this condition were asked to list their own positive thoughts about it.

In contrast, in the negative thoughts condition, the message emphasized various risks of comprehensive exams. For example, the message stated that "the prospect of a comprehensive exam clearly appears to be stressful and overwhelming, leading students to achieve less and faculty to be less effective," as well as "students from institutions with comprehensive exams are less likely to be accepted into good graduate programs," and "in recent years, starting salaries of students from other institutions with comprehensive exams have been, on average, three thousand to four thousand dollars lower than starting salaries for students graduating from comparable institutions without the exams." After reading this negative message, participants in this condition were asked to list their thoughts about instituting the exams. Previous research in persuasion has shown that this induction is an effective procedure to ensure participants generate relatively positive or negative evaluative 
responses toward topics like comprehensive exams (Briñol et al., 2012; Killeya \& Johnson, 1998). ${ }^{2}$

\section{Perceived Validity of Thoughts}

Following the task of listing thoughts, participants indicated the validity of their thoughts (metacognitive confidence) about comprehensive exams by answering the two following questions: "How confident are you about your thoughts regarding comprehensive exams?" $(1=$ "Not at all confident" to $7=$ "Extremely confident"), and "How certain are you in the thoughts that you have just generated?" $(1=$ "Not certain at all" to $7=$ "Extremely certain"). The two measures were significantly correlated $(r=.68, p<0.001)$ and were thus averaged to form one single measure of perceived validity. Similar items have been used to measure thought confidence in other self-validation studies revealing that perceived thought validity can be measured by merely asking participants to rate their thought confidence (e.g., Petty et al., 2002; Horcajo et al., 2020; Requero et al., 2020; see also Graft et al., 2017). Responses to this composite index were scored so that higher values represented the perception of more validity of thoughts.

\section{Dependent Variable: Exam Performance}

Participants were asked to do a knowledge test on psychology. This dependent measure was selected because of its relevance for the object of thought in this study (i.e., thoughts about comprehensive exams in one's major). This test included twelve questions about psychology. Participants' correct responses to these questions were summed to create the exam performance index. That is, participants' performance was assessed by counting the number of questions that they correctly solved, ranging from 0 to 12 correct answers (for similar procedures of assessing performance based on standardized tests, see Callender et al., 2016; Elliot et al., 1999; Hacker et al., 2000; Veenman et al., 1997).

\section{Results}

The number of questions correctly answered in the exam was submitted to a hierarchical regression analysis, with thought valence (dichotomous), perceived validity of thoughts (continuous), and the interaction term (i.e., Thought Valence $\times$ Perceived Validity of Thoughts) as the predictor variables. Main effects were interpreted in the first step of the regressions and the two-way interaction in the final step (Cohen \& Cohen, 1983). Results showed a significant interaction between thought valence and perceived validity of

\footnotetext{
${ }^{2}$ At the end of the study, participants completed a manipulation check for thought valence. Specifically, participants had to answer a question about the perceived valence of their thoughts about exams (positive or negative) using a dichotomous scale: "How did you perceive the thoughts you had about exams?" $(0=$ Negative, $1=$ Positive $)$. Participants' perception of their own thoughts was submitted to a logistic binary regression analyses using thought valence (Positive vs. Negative), perceived thought validity (continuous), and the interaction term (i.e., Thought Valence $\times$ Perceived Thought Validity) as predictor variables. Results revealed a main effect of thought valence, $B=3.414$ (95\% CI: $2.150,4.678), z=5.293, p<.001$, such that participants in the positive thoughts condition perceived their thoughts to be more positive than those in the negative thoughts condition. No other effects reached significance $(p s>.086)$.
} 


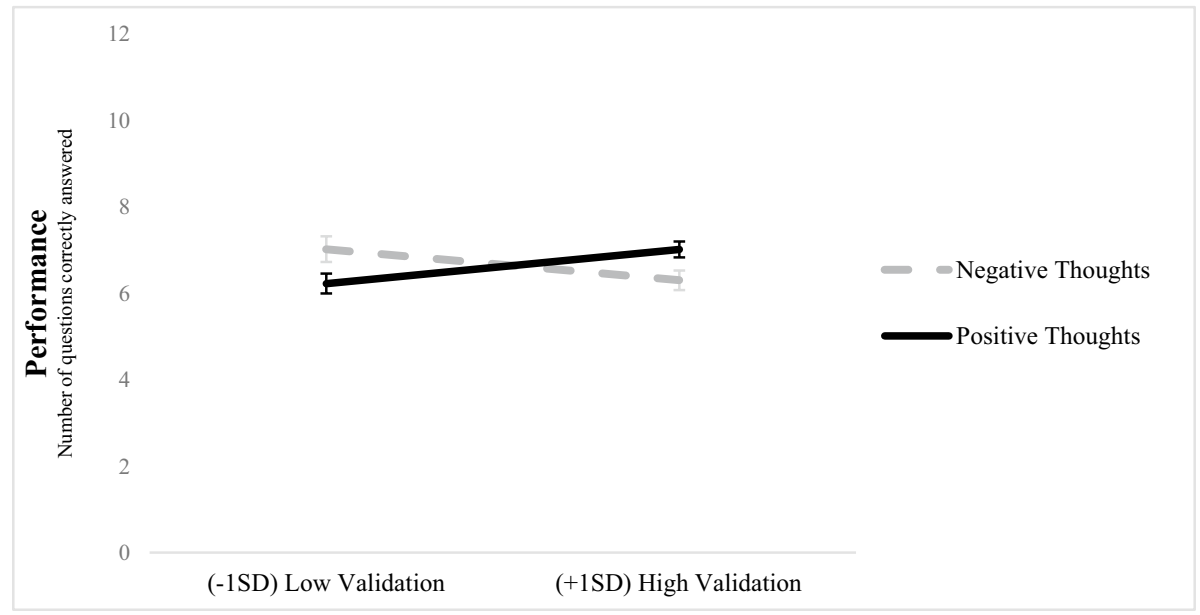

Fig. 1 Performance on the Exam About Psychology as a Function of Thought Valence (Positive vs. Negative) and Perceived Thought Validity (plotted at +1 and -1 SD from the mean) in Study 1. Note. Error bars represent standard errors.

thoughts on participants' psychology test performance, $B=0.785$ (95\% CI: $0.299,1.270)$, $t(123)=3.200, p=.002$, Cohen's $f^{2}=.083$. As illustrated in Fig. 1, participants' thoughts predicted the number of questions correctly solved when they perceived those thoughts to have high validity $(+1 \mathrm{SD}), B=0.712(95 \% \mathrm{CI}: 0.054,1.370), t(123)=2.141, p=.034$, but the effect was reversed when they reported low thought validity $(-1 \mathrm{SD}), B=-0.796(95 \%$ CI: $-1.454,-0.138), t(123)=-2.394, p=.018$.

Analyzed differently, this interaction also showed that, among participants who were randomly assigned to generate positive thoughts, as perceived thought validity increased, more questions were solved correctly, $B=0.411$ (95\% CI: $0.067,0.754$ ), $t(123)=2.365$, $p=.020$. In contrast, for participants in the negative thought condition the effect was the opposite. As perceived validity in negative thoughts increased, fewer questions were solved correctly, $B=-0.374$ (95\% CI: $-0.717,-0.031), t(123)=-2.161, p=.032$. No other effects emerged $(p s \geq .863)$.

\section{Discussion}

The results of this study are consistent with the self-validation hypothesis, and showed that the extent to which people see their primary cognitions (thoughts about exams) as valid affects the impact of those thoughts on performance. Specifically, the valence of students' thoughts had a greater impact on the number of questions about psychology correctly answered when the validity of thoughts (metacognitive confidence) was perceived to be relatively high. In contrast, when perceived validity was relatively low, the effect was reversed. Viewing this interaction differently, generating positive thoughts improved performance as the perceived validity of those positive thoughts increased. However, increasing the perceived validity (metacognitive confidence) associated with negative thoughts reduced performance. 
In sum, this study was informative in affirming the idea that measuring the validity with which thoughts are held (metacognitive confidence) can lead to increased predictability of the effects of manipulated thoughts on performance in an academic context. Nevertheless, because participants' validity of thoughts was measured, it is possible that other, unmeasured factors (e.g., self-esteem, intelligence, etc.) may have been confounded with reported metacognitive confidence. Therefore, in the next study, we manipulated both thought validity and thought valence in order to more accurately infer the causal role of both variables. Additionally, in the next study we varied the object of thought and the type of performance assessed to gain generalization across topics, materials, and inductions. Finally, we included a neutral control group to examine the extent to which the obtained finding was mostly due to the attenuation effect of low perceived validity (invalidation) or the magnifying effect of high perceived validity (validation).

\section{Study 2}

Study 2 aimed to replicate and extend the findings of Study 1, examining the causal role of thought-validation (metacognitive confidence). For that purpose, Study 2 used a full experimental design by manipulating thought validation as well as thought valence. Furthermore, this study introduced a number of other important changes designed to generalize across procedures, and to gain further understanding of the obtained effects.

In this study, participants were first asked to think about their best or worst qualities as future job candidates (primary cognitions). Therefore, instead of generating thoughts about exams, in this study participants thoughts were about themselves. After the thought valence induction, perceived validity of their thoughts was manipulated (rather than measured as in the previous study) to be relatively high or low. Specifically, participants were randomly assigned to one of the three conditions designed to vary the perceived validity of their thoughts: validation, invalidation, or control. Finally, instead of measuring knowledge as in the previous study with a psychology exam, participants in this experiment were asked to solve problems with geometric figures (shapes task) that were designed to simulate a job-relevant screening test (see Martens et al., 2006, Preckel et al., 2006; for similar measure of performance).

Despite all the variations in inductions, we predicted the same interaction between thought valence and thought validation in affecting performance. Specifically, it was expected that the valenced thoughts of participants assigned to the high confidence condition (validation) would have more impact on performance compared to the thoughts of those assigned to the low confidence (invalidation) condition. Control condition participants were expected to perform in between the validation and invalidation conditions suggesting a role both for validity and invalidity in affecting thought use (i.e., validation increasing it and invalidation decreasing it).

\section{Method}

\section{Participants and Design}

Two hundred and forty-six undergraduates in psychology (211 females, and 35 males) participated anonymously in this study. The age of the participants ranged from 17 to 29 
$\left(M_{\text {age }}=19, S D=1.51\right)$. All of them were randomly assigned to a 2 Thought Valence (Positive vs. Negative self-relevant thoughts) $\times 3$ Validity of Thoughts (Validation vs. Invalidation vs. Control) factorial design. Performance was measured as the dependent variable. A power analyses was conducted using $\mathrm{G}^{*}$ Power (Faul et al., 2007). Based on the average effect size for the interaction in the pilot study (Cohen's $f^{2}=.043$ ) and Study 1 (Cohen's $\left.f^{2}=.083\right)$, results indicated that the desired sample size with .80 power was $N=157$ participants. Our final sample size approximately doubled the estimated one (246 participants) because we wanted to be sure we had enough participants to detect the effect even if it was smaller than anticipated given this first manipulation in this context of thought confidence. ${ }^{3}$

\section{Procedure}

Permission to conduct the study was provided by the university institutional ethics committee before the study began. Upon arrival, participants were told that the study was about self-evaluation in professional contexts. The self is a topic of high personal relevance to participants (Petty \& Cacioppo, 1979), and even more so in the context of students facing future prospects in the job market (Briñol et al., 2009). This is important because, as noted, self-validation processes are more likely to operate when thinking is relatively high. In this study, participants were asked to think about their best or worst qualities as future job candidates. These self-relevant thoughts served as the primary cognitions. Following this thought valence manipulation, participants were randomly assigned to one of the three conditions designed to vary the perceived validity of their primary cognitions: validation, invalidation, or control. Finally, all participants were asked to complete up to four problems as the performance measure. After these problems and some ancillary questions were completed, participants were thanked, debriefed, and dismissed.

\section{Independent Variables}

\section{Thought Valence}

Participants were asked to list either three positive or three negative personal characteristics they possessed as future job candidates. In the positive thought condition, they were asked to list the strengths, skills, and abilities they expected to have in facing the job market. In the negative thought condition, they were asked to list the weaknesses, flaws, and limitations they anticipated having when facing the job market. All participants were told that this was an important task and were asked to think carefully as they listed their characteristics. As noted, previous research has shown that self-evaluations can vary as a result of thinking about one's strengths or weaknesses (e.g., Tice, 1992; Vohs et al., 2005), and this particular procedure has been used successfully in previous self-validation studies to influence self-evaluations (e.g., Briñol \& Petty, 2003; Briñol et al., , 2009, 2013; Hermann et al., 2002). ${ }^{4}$

\footnotetext{
${ }^{3}$ If we analyze the data with the first 157 participants, the two-way interaction between thought valence and validity of thoughts on performance was significant, $F(2,151)=5.599, p=.005, \eta_{\rho}{ }^{2}=.069$ and showed the same pattern of that reported in the main text.

4 At the end of the study, participants completed a manipulation check to ensure the manipulation created the intended pattern of thoughts. Specifically, participants had to answer a question about the perceived valence of their thoughts using the scale: "How would you rate the thoughts you had while listing your
} 


\section{Validity of Thoughts}

The validity of primary cognitions served as the secondary, metacognitive variable. Participants were randomly assigned to one of the three conditions designed to vary perceived validity of the thoughts generated. In each of these conditions, participants received different instructions and had to answer different questions. The instructions and questions were designed to lead participants to think that the validity of their thoughts was high or low or were irrelevant to validity.

In the validation condition, the title of the instructions was "confidence in your thoughts." Participants in this condition were asked to rate the validity of their thoughts using a series of questions in which the responses were framed to be high in all cases. That is, the responses provided to answer questions in this condition were framed to always imply high degrees of validity, confidence, and certainty. For example, one question was "How certain are you in the thoughts that you have just generated?" The answer to this question was anchored from $1=$ "Somewhat certain" to $9=$ "Extremely certain." Therefore, the minimum score that participants could answer already implied some degree of certainty. Given that the minimum anchor was already relatively high, responding to these questions was expected to make participants appear as if they had by default relatively high levels of confidence, certainty, rightness, and validity. This validation procedure is a novel, subtle induction of thought confidence and is based on similar inductions in which the question wording or anchors presented to participants are varied to imply the presence or absence of a psychological state (e.g., Salancik \& Conway, 1975). In this case, the induction was designed to increase perceived thought validity and subsequent thought reliance by leading participants to think that they had high levels of thought confidence.

In the invalidation condition, "separate from your thoughts" was the highlighted title of the instructions and participants were asked to rate the extent to which they were separated from the self-relevant thoughts they just generated. Participants in this condition also answered a series of questions but this time responses implied that the participants were distant, separated, and disengaged from their thoughts. For example, one question was "How distanced are you from the thoughts that you have just generated?" (1 = "Somewhat distanced" to $9=$ "Extremely distanced"). Therefore, regardless of the scores provided by participants, all responses implied some level of distance from their thoughts. This invalidation condition was designed to reduce the perceived validity of thoughts and subsequent thought usage. Although this induction was also rather subtle, it was designed in accord with previous research revealing that creating distance from thoughts (either through mindfulness, cleansing, or other means) decreases the use of thoughts (Bernstein et al., 2015; Lee \& Schwarz, 2021). Also, research on self-persuasion has demonstrated that physical distance (Briñol et al., 2013), and other forms of separation from one's thoughts, can decrease the use of both positive and negative thoughts affecting self-evaluation (Gascó et al., 2018; Paredes et al., 2019; Santos et al., 2019).

Footnote 4 (continued)

characteristics as a job candidate?" (1=Negative, 9=Positive). One participant did not complete this measure, so it was excluded from the analysis. The 2 Thought Valence (Positive vs. Negative) $\times 3$ Thought Validity (Validation vs. Invalidation vs. Control) ANOVA revealed a main effect for the thought valence manipulation, $F(2,239)=120.315 ; p<.001, \eta_{\rho}{ }^{2}=.335$, such that participants in the positive thought condition perceived their thoughts to be more positive than those in the negative thought condition. No other effects reached significance ( $p s>.140)$. 
Finally, in the control condition, participants were instructed to "read the following statements" and were merely asked to read a few neutral statements unrelated to distance or validity. For example, one of the statements was "you will find the instructions regarding what to do for each task."

\section{Dependent Variable: Performance}

Participants had to solve four problems that consisted of identifying the missing element that completed a pattern of geometric figures (shapes task). For example, one of the problems presented a combination of triangles and squares which changed its position and color following a pattern. To choose the correct item that completed the pattern, students had to guess the underlying logic in the sequence of shapes presented (for a similar assessment of performance see Martens et al., 2006; Preckel et al., 2006). The number of problems correctly solved was the dependent measure of the study, ranging from 0 to 4 . Importantly, this task was presented as one that was relevant to potential job performance.

\section{Results}

A 2 Thought Valence (Positive vs. Negative) $\times 3$ Validity of Thoughts (Validation vs. Invalidation vs. Control) ANOVA was conducted on participants' performance. The analysis revealed that thought valance did not affect performance significantly as a main effect ( $p \geq .174)$. There was no main effect for the thought validation manipulation either $(p \geq .713)$. Most importantly, the results showed a significant interaction between thought valence and validity of thoughts, $F(2,240)=5.929, p=.003, \eta_{\rho}^{2}=.047$ (see Fig. 2).

To fully interpret this interaction, further contrasts were conducted. We first examined only the validation and invalidation conditions along with thought valence and results

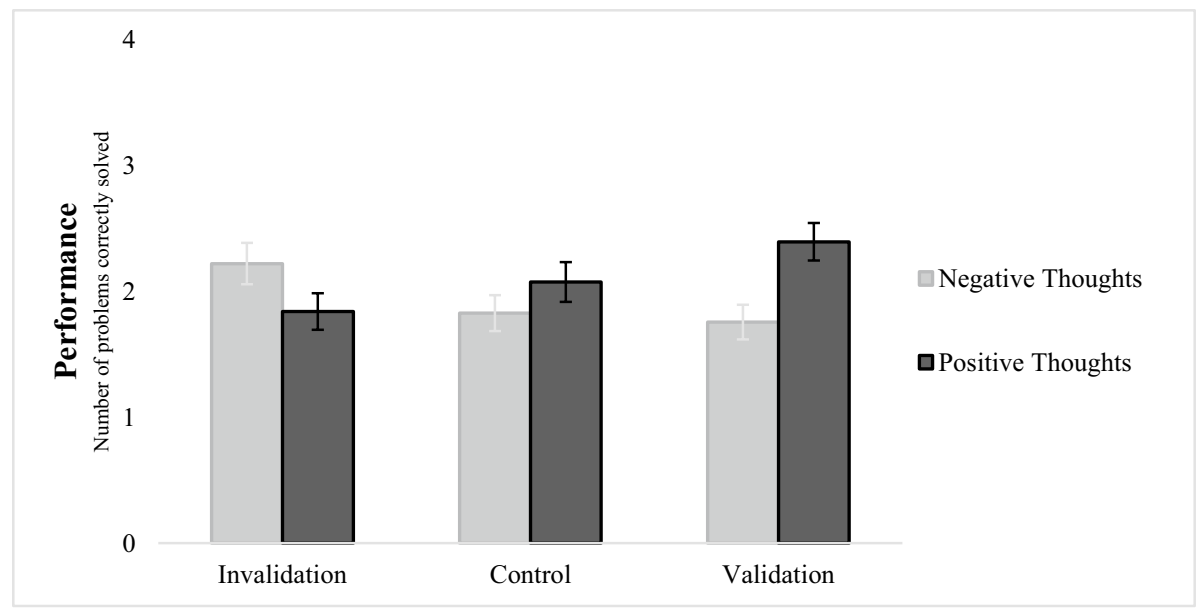

Fig. 2 Performance on the Geometric Shapes Task as a Function of Thought Valence (Positive vs. Negative) and Validity of Thoughts (Invalidation vs. Control vs. Validation) in Study 2. Note. Error bars represent standard errors. 
revealed a significant interaction between thought valence and validity of thoughts, $t(240)=3.385, p=.001$. This interaction conceptually replicated the two-way interaction pattern observed in Study 1. This interaction showed that the effect of thought valence on performance was greater for participants in the validation condition than for those in the invalidation condition. For thought-validation participants, those who generated positive thoughts solved more problems correctly $(M=2.40, S D=0.90,95 \% \mathrm{CI}=[2.11,2.68])$ than did those who generated negative thoughts $(M=1.75, S D=0.79,95 \% \mathrm{CI}=[1.43$, $2.09]), F(1,240)=8.263, p=.004, \eta_{\mathrm{p}}{ }^{2}=.033$. However, for the invalidation condition a non-significant trend in the opposite direction emerged: participants who generated positive thoughts tended to solve fewer problems correctly $(M=1.84, S D=0.96,95 \%$ $\mathrm{CI}=[1.56,2.13])$ than those who generated negative thoughts $(M=2.22, S D=1.10,95 \%$ $\mathrm{CI}=[1.94,2.50]), F(1,240)=3.519, p=.062, \eta_{\mathrm{p}}^{2}=.014$.

The interaction between thought valence and validity of thoughts was also significant when comparing control and invalidation conditions. This interaction revealed that the effect of thought valence on performance was greater for participants in the control condition than for those in the invalidation condition, $t(240)=2.133, p=.034$. However, the interaction between thought valence and validity of thoughts was not significant when control conditions were compared to validation conditions, $t(240)=1.273, p=.204$.

Analyzing the overall Thought Valence $\times$ Validity of Thoughts interaction differently, for the participants who generated positive thoughts, those who received the validation induction solved more problems correctly $(M=2.40, S D=0.90,95 \% \mathrm{CI}=[2.11,2.68])$ than those who received the invalidation induction $(M=1.84, S D=0.96,95 \% \mathrm{CI}=[1.56$, 2.13]), $F(1,240)=7.274, p=.007, \eta_{\mathrm{p}}{ }^{2}=.029$, but did not differ from those assigned to the control group $(M=2.07, S D=0.99,95 \% \mathrm{CI}=[1.77,2.37]), F(1,240)=2.314, p=.130$, $\eta_{\mathrm{p}}{ }^{2}=.010$. The control group also did not differ from the invalidation condition, $F(1$, $240)=1.249, p=.265, \eta_{\mathrm{p}}{ }^{2}=.005$. In contrast, among the participants who generated negative thoughts, those who received the validation induction solved fewer problems correctly $(M=1.75, S D=0.79,95 \% \mathrm{CI}=[1.43,2.09])$ than those who received the invalidation induction $(M=2.22, S D=1.10,95 \% \mathrm{CI}=[1.94,2.50]), F(1,240)=4.472, p=.035$, $\eta_{\mathrm{p}}{ }^{2}=.018$, but did not differ from those assigned to the control group $(M=1.83, S D=0.92$, $95 \% \mathrm{CI}=[1.53,2.12]), F(1,240)=0.102, p=.749, \eta_{\mathrm{p}}{ }^{2}=.001$. Participants assigned to the invalidation condition tended to solve fewer problems correctly than did those from the control group, $F(1,240)=3.604, p=.059, \eta_{\mathrm{p}}^{2}=.015$.

\section{Discussion}

The results of this study are consistent with the self-validation hypothesis and provide a conceptual replication and extension of the findings obtained in Study 1. This study provided additional support for a differential effect of thought validity as a function of the valence of thoughts that were accessible. We showed that the validation condition affected reliance on previously generated thoughts more than the invalidation condition, influencing subsequent performance. The control condition tended to fall in between validation and invalidation as expected. Viewing this interaction differently, generating positive thoughts (self-strengths) improved performance when reliance on those positive thoughts was manipulated to be high (validation) rather than low (invalidation). However, increasing the validity associated with negative thoughts (self-weaknesses) tended to reduce performance compared to invalidation. Again, the control condition fell in between. 
Most importantly, this study used an experimental induction of thought validation rather than relying on a measurement approach thereby providing some evidence for a causal role of validation processes in affecting the extent to which primary cognitions determine performance. In sum, despite changing the way that positive and negative thoughts were salient, the approach to validating thoughts, and the object of thought, the validation induction affected the validity of previously activated thoughts, affecting subsequent performance.

\section{Study 3}

Study 3 was designed to replicate and extend the prior findings by including a more complete and validated measure of performance as the dependent variable, as well as adding a measure of the proposed mediator (perceived thought validity). In this study, participants were first asked to think about their best or worst qualities as students. Therefore, instead of focusing on thoughts about exams, or self-relevant thoughts as potential job candidates, in this experiment we asked participants to think about their qualities as students as a manipulation of their primary cognitions. After this thought valence induction, the perceived validity of the primary cognitions listed (metacognitive confidence) was manipulated to be relatively high or low. Specifically, participants were randomly assigned to either recall past episodes of confidence or past episodes of doubt (Petty et al., 2002; Requero et al., 2020). As a dependent measure, participants in this experiment were asked to solve a test consisting of 30 multiple-choice questions from the Graduate Record Examination (Jamieson et al., 2010). By having a more reliable and balanced measure of performance we expected to avoid possible floor and ceiling effects that could result if a small number of measures are too easy or difficult. Finally, this study also included a new measure of the proposed metacognitive mediator (perceived thought validity) to examine the role of this metacognitive assessment in performance.

Despite all the variations, we predicted that participants assigned to the validation condition should magnify the effects of valenced thoughts on performance relative to those assigned to the invalidation condition. Furthermore, we expected that these effects of validity of thoughts on performance would be mediated by the overall perceived validity with which participants reported holding the thoughts they had listed.

\section{Method}

\section{Participants and Design}

Three hundred and four undergraduates in psychology (271 females, 30 males, and 3 unidentified) participated anonymously in this study. The age of the participants ranged from 17 to $36\left(M_{a g e}=20, S D=1.68\right)$. Participants were randomly assigned to a 2 Thought Valence (Positive vs. Negative) $\times 2$ Validity of Thoughts (Validation vs. Invalidation) factorial design. Performance in responding to math and verbal GRE questions was measured as the key dependent variable. A power analysis was conducted based on the average interaction effect obtained in the prior studies. Analyses were conducted using $G^{*}$ Power (Faul et al., 2007) entering the interaction effect size across studies (Cohen's $f^{2}=.057$ ). Results on this analysis suggested that the desired sample size with .80 power is $N=140$. We aimed 
to double this estimate and somewhat exceeded this goal because data collection continued until the end of the week when the sample size was expected to be reached. ${ }^{5}$

\section{Procedure}

Permission to conduct the study was provided by the university institutional ethics committee before the study began. Upon arrival, participants were told that the study was about self-evaluation. First, participants were asked to think about their best or worst qualities as students (primary cognition). Following this thought valence induction, participants were randomly assigned to recall past episodes of confidence (validation condition) or doubt (invalidation condition). This manipulation was designed to vary the perceived validity of the thoughts previously listed (metacognitive confidence). After these two inductions, participants were asked to complete a test consisting of 30 multiple-choice questions from the Graduate Record Examination (Educational Testing Service, 1999) and to report their perceived thought validity (measure of the proposed metacognitive mediator). The number of questions correctly answered served as the dependent measure. Participants completed ancillary questions, and were thanked, debriefed, and dismissed.

\section{Independent Variables}

\section{Thought Valence}

Participants were asked to list either three positive or three negative personal characteristics they possessed as students, an induction similar to that employed in Study 2 which had participants list their strengths and weaknesses as job candidates. These self-relevant thoughts were the primary cognitions of this study. Specifically, in the positive thought condition, participants were asked to list the strengths, skills, and abilities they have regarding their academic career. In the negative thought condition, they were asked to list the weaknesses, flaws, and limitations they have when considering their academic career. All participants were told that this was an important task and were asked to think carefully as they listed their characteristics. ${ }^{6}$

\footnotetext{
5 Analyzing the data with only the first 140 participants, the two-way interaction between thought valence and validity of thoughts on performance was already significant, $F(1,136)=4.878, p=.029, \eta_{\rho}{ }^{2}=.035$. For participants assigned to the thought-validation condition, those who generated positive thoughts solved correctly more questions than did those who generated negative thoughts, $F(1,136)=5.762, p=.018$, $\eta_{\rho}{ }^{2}=.041$. Within the invalidation condition there were no differences between those who generated positive and those who generated negative thoughts, $F(1,136)=0.614, p=.435, \eta_{\rho}{ }^{2}=.004$. This pattern replicated the results reported in the main text for the full sample of this study.

6 At the end of the study, participants completed a manipulation check to ensure the manipulation created the intended pattern of thought valence. Specifically, participants had to answer a question about the perceived valence of their thoughts using the scale: "How would you rate the thoughts you listed as a job candidate?" (1=Negative, 9=Positive). The 2 Thought Valence (Positive vs. Negative) $\times 2$ Validity of Thoughts (Validation vs. Invalidation) ANOVA revealed a main effect for the thought valence manipulation, $F(1,300)=54.310 ; p<.001, \eta_{\rho}{ }^{2}=.153$, such that participants in the positive thought condition perceived their thoughts to be more positive than those in the negative thought condition. No other effects reached significance $(p s>.204)$.
} 


\section{Validity of Thoughts}

Participants were randomly assigned to either validity or invalidity conditions. In the validation condition, participants were asked to describe a past personal episode in which they felt confidence in their thoughts. In the invalidation condition, participants were asked to describe a past personal episode in which they felt doubt. Prior research has shown that this manipulation following a thought listing can lead people to misattribute the high or low confidence induced by the writing task to the thoughts listed previously (metacognitive confidence), even though these thoughts are unrelated to the episodes described (Petty et al., 2002; Requero et al., 2020).

\section{Dependent Variables}

\section{Performance}

Participants in this study were asked to solve 30 multiple-choice questions from the standardized math and a verbal performance test of the Graduate Record Examination (Educational Testing Service, 1999). The math test we used consisted of 20 multiple-choice problems taken from the quantitative reasoning section of practice GREs (Jamieson \& Harkins, 2009). The verbal performance test we used consisted of 10 multiple-choice word problems taken from the verbal reasoning section of practice GREs (e.g., Croizet \& Claire, 1998; Mrazek et al., 2013). This selection of 30 items including both math and verbal questions was used previously by Jamieson et colleagues (2010). The order of presentation of these questions was randomized and all participants responded to the same questions. Responses were coded as correct or incorrect (wrong answers, or no response), giving a minimum total correct score of 0 and a maximum of 30 . The average number of questions solved was close to $13(M=12.71, S D=3.52)$.

\section{Perceived Thought Validity}

To assess overall perceived thought validity, participants answered the two items previously used by Briñol et colleagues (2007). In particular, we asked participants, "How valid do you believe the thoughts you listed are ( $1=$ not at all valid, $9=$ extremely valid $)$ ?" and "How confident are you in the thoughts that you listed $(1=$ not at all confident, $9=$ extremely confident)?" We averaged these ratings to form a single index of overall perceived thought validity for each participant, $r(302)=.378, p<.001$. Answering these questions requires participants to reflect on their own thoughts and these questions are considered well-established measures of metacognitive perceptions (Fleming \& Lau, 2014; Rucker et al., 2011). Higher values on this index indicated that participants perceived their thoughts to be more valid.

\section{Results}

\section{Performance}

A 2 Thought Valence (Positive vs. Negative) $\times 2$ Validity of Thoughts (Validation vs. Invalidation) ANOVA was conducted on participants' performance. This analysis revealed 


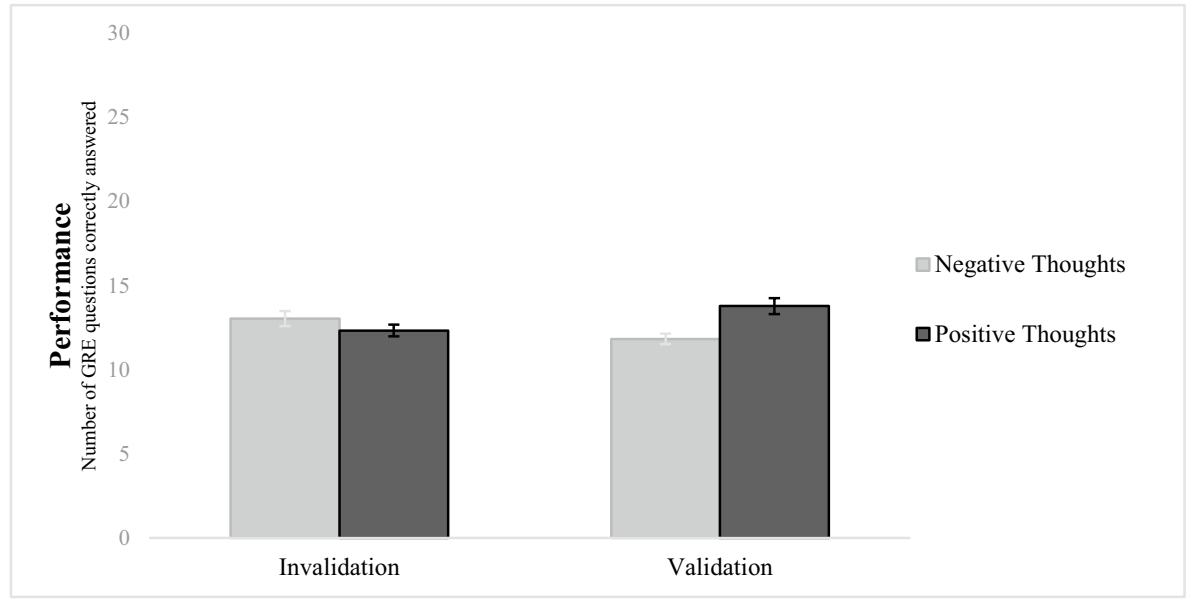

Fig. 3 Performance on the GRE Questions as a Function of Thought Valence (Positive vs. Negative) and Validity of Thoughts (Validation vs. Invalidation) in Study 3. Note. Error bars represent standard errors.

that there were no significant main effects of either thought valence or thought validity $(p s \geq .118)$. The results showed the predicted significant interaction between thought valence and validity of thoughts, $F(1,300)=11.152, p=.001, \eta_{\rho}^{2}=.036$ (see Fig. 3).

As illustrated in Fig. 3, for participants assigned to the thought-validation condition, those who generated positive thoughts solved correctly more questions $(M=13.78$, $S D=4.02,95 \% \mathrm{CI}=[12.97,14.58])$ than did those who generated negative thoughts $(M=11.82, S D=2.71,95 \% \mathrm{CI}=[11.02,12.62]), F(1,300)=11.562, p=.001, \eta_{\rho}^{2}=.037$. Within the invalidation condition there were no differences between those who generated positive $(M=12.32, S D=3.24,95 \% \mathrm{CI}=[11.59,13.05])$ and those who generated negative thoughts $(M=13.03, S D=3.78,95 \% \mathrm{CI}=[12.22,13.83]), F(1,300)=1.637, p=.202$ $\eta_{\rho}^{2}=.005$.

Analyzing the overall interaction differently, generating positive thoughts improved performance when validation of those positive thoughts was manipulated to be high $(M=13.78, S D=4.02,95 \% \mathrm{CI}=[12.97,14.58])$ rather than low $(M=12.32, S D=3.24$, $95 \% \mathrm{CI}=[11.59,13.05]), F(1,300)=6.963, p=.009, \eta_{\rho}^{2}=.023$. However, for the participants who generated negative thoughts, the effect of thought validity was the opposite. That is, generating negative thoughts decreased performance when validation of those negative thoughts was manipulated to be high $(M=11.82, S D=2.71,95 \% \mathrm{CI}=[11.02,12.62])$ rather than low $(M=13.03, S D=3.78,95 \% C I=[12.22,13.83]), F(1,300)=4.395$, $p=.037, \eta_{\rho}^{2}=.014$.

\section{Perceived Thought Validity}

As expected, participants reported greater confidence in their thoughts in the thought validation condition $(M=6.77, S D=1.74,95 \% \mathrm{CI}=[6.49,7.04])$ than in the thought invalidation condition $(M=6.26, S D=1.60,95 \% \mathrm{CI}=[6.02,6.54]), F(1,300)=6.425, p=.012$, $\eta_{\rho}^{2}=.021$. No other effects reached significance $p s \geq .176$. 


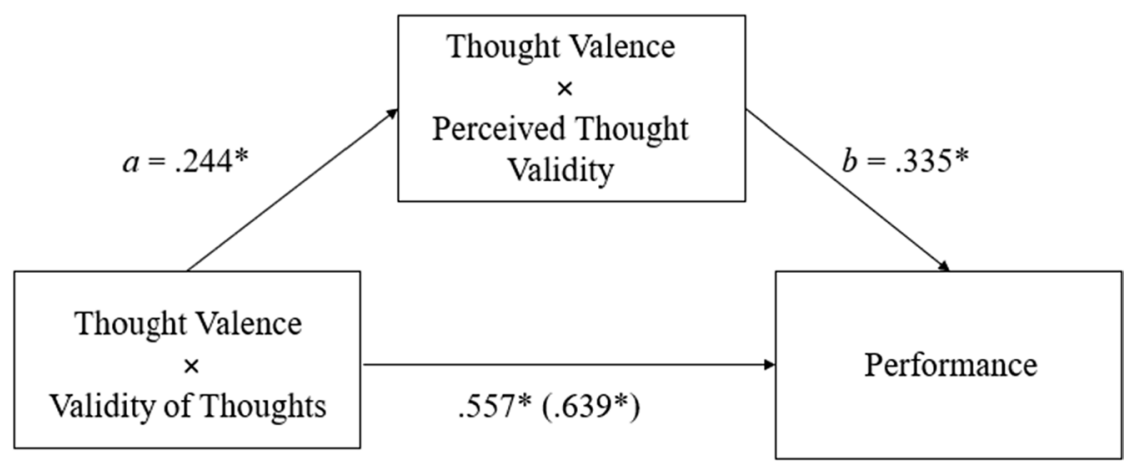

Fig. 4 Mediation Model Showing the Effect of Thought Valence $\times$ Validity of Thoughts, as Mediated by Thought Valence $\times$ Perceived Thought Validity on Performance in Study 3. Note. The figure in the parenthesis is the total effect of "Thought Valence $\times$ Validity of Thoughts" on "Performance." *p $<.050$

\section{Mediation Analysis}

To examine whether the extent of perceived thought validity (metacognitive confidence) mediated the effect of the key theorized interaction on the performance measure, we conducted a mediated moderation test using bootstrapping methods (Muller et al., 2005). In this procedure, manipulated thought valence and validity of thoughts were both contrast coded (i.e., negative thoughts / low validity $=-1$, positive thoughts / high validity $=1$ ) and perceived thought validity was mean-centered. To test the hypothesized mediation by perceived thought validity (metacognitive confidence), we conducted a biased corrected bootstrapping procedure with 10,000 bootstrap re-samples using Hayes process macro (Model 4; Preacher \& Hayes, 2004; Shrout \& Bolger, 2002). In this analysis, Thought Valence $\times$ Validity of Thoughts was an independent variable, performance was a dependent variable, and Thought Valence $\times$ Perceived Thought Validity was a mediating variable (see Fig. 4). Thought valence, validity of thoughts and perceived thought validity were included as covariates. This approach includes procedures that compute a $95 \% \mathrm{CI}$ around the indirect effect and mediation is indicated if this CI does not include zero. As predicted, the result of this bootstrapping procedure revealed that the $95 \%$ CI of the indirect effect (i.e., the path through the mediator) did not include zero (Indirect Effect $\mathrm{a} \times \mathrm{b}=.082,95 \%$ $\mathrm{CI}=[0.016,0.205])$. Therefore, the mediation by metacognitive confidence is supported as plausible. $^{7}$

\footnotetext{
${ }^{7}$ For the math GRE questions alone, the mediation was still supported as plausible (Indirect Effect $\mathrm{a} \times \mathrm{b}=.046,95 \% \mathrm{CI}=[0.007,0.125])$. For the verbal GRE questions alone, the mediation was also supported as plausible (Indirect Effect $\mathrm{a} \times \mathrm{b}=.036,95 \% \mathrm{CI}=[0.001,0.104]$ ). For comparison purposes, we also examined whether the key interaction in this and the other studies was mediated by the continuous measure of thought valence. No evidence of mediation by this measure of perceived thought valence was observed in Study 2 (Indirect Effect $\mathrm{a} \times \mathrm{b}=.029,95 \% \mathrm{CI}=[-0.002,0.098]$ ), or in Study 3 (Indirect Effect $\mathrm{a} \times \mathrm{b}=-.021$, $95 \% \mathrm{CI}=[-0.096,0.006]$.
} 


\section{Discussion}

Despite changing the content of primary cognitions (self as student) and the precise procedure to manipulate secondary cognitions, the results again supported the self-validation predictions. As expected, the validation induction affected reliance on previously activated primary cognitions (thoughts about the self as a student), influencing subsequent performance. Regarding the invalidation condition, results showed that previously activated thoughts did not have any effect on performance. Viewing this interaction differently, generating positive thoughts improved performance when reliance on those primary cognitions was manipulated to be high rather than low. However, the same induction of metacognitive validity decreased performance for negative thoughts. That is, the effect of validity of thoughts on performance was significant for both positive and negative thoughts.

This final experiment also showed that changes in the metacognitive measure of perceived thought validity served as a plausible mediator of the impact of thought valence and the validity of thoughts manipulations on participants' performance. Therefore, this study provided convergent evidence for the key interaction and extended the contribution by providing meditational evidence consistent with the proposed process.

\section{General Discussion}

Taken together, these three studies are consistent with the idea that metacognitive thought confidence can lead to opposite academic performance findings depending on whether it validates positive or negative performance-relevant thoughts. The pattern across all studies was that when primary cognitions were positive (positive thoughts about exams, selfstrengths as a job candidate or as a student), metacognitive confidence (whether measured or manipulated) improved performance. However, when thoughts were negative (negative thoughts about exams, self-weaknesses), the same metacognitive confidence reduced performance. ${ }^{8}$ Thus, promoting feelings of confidence in students can produce the desired outcomes on performance or backfire depending on whether it validates positive or negative previously generated thoughts. Importantly, this research also provided meditational evidence of the proposed mechanism. Specifically, Study 3 showed that changes in perceived thought validity mediated the impact of the interaction of the two manipulations on participants' performance. Based on these findings, we argue that thought validation can help in specifying why and when metacognitive confidence would increase or decrease performance in academic settings.

\footnotetext{
8 To provide maximum power, we combined the data across all studies. First, although our samples were composed of more women than men in each study, we did not expect nor find any gender differences in this set of studies. That is, when collapsing the data of the three studies (dichotomizing the continuous variables of Study 1 at the median, eliminating participants assigned to the control group in Study 2, and including type of study and gender as additional predictors), the results revealed that the predicted two-way interaction between thought valence and validity of thoughts was significant overall, $F(1,568)=16.909, p \leq .001$, $\eta_{\rho}{ }^{2}=.029$, and also for both women, $F(1,514)=22.585, p \leq .001, \eta_{\rho}{ }^{2}=.042$, and men, $F(1,54)=11.999$, $p=.001, \eta_{\rho}^{2}=.182$. Decomposing the overall two-way interaction by thought valence, we observe that the effect of validity of thoughts was significant both for positive, $F(1,568)=8.753, p=.003, \eta_{\rho}{ }^{2}=.015$; and negative thoughts, $F(1,568)=8.171, p=.004, \eta_{\rho}{ }^{2}=.014$. Finally, this overall two-way interaction was not further qualified by either type of study, $p=.502$, nor gender $p=.303$.
} 
The findings were robust across topics, including thoughts about exams in one's major in the first study, thoughts about the self as a future job candidate in the second study, and thoughts about the self as a student in the third. Furthermore, the same outcome was observed regardless of the type of test employed (e.g., knowledge, geometric shapes problems, or math and verbal GRE questions). In sum, this research showed the same pattern of results using different thought objects, different inductions, and different measures of performance. These findings demonstrate that there is considerable value in differentiating between merely having thoughts and engaging in metacognitive assessment of those thoughts. Although promoting confidence to becoming more successful and productive has become a popular approach (Burgmer \& Englich, 2012; Körner et al., 2020; Lammers et al., 2013; Peper et al., 2018) the present studies suggest that increasing confidence will not be beneficial universally.

Recognizing that promoting feelings of confidence in students can have opposite effects on performance depending on the salience of the thoughts (positive versus negative) in a person's mind is important for designing future interventions and it is also potentially relevant for explaining some inconsistent effects in the previous literatures. In fact, rather than being inherently beneficial, variables associated with confidence used in prior research have led to positive outcomes in some cases but have also led to negative outcomes in other cases. For example, in a classic review, Hansford and Hattie (1982) concluded that the relationship between self-esteem (a variable often associated with confidence; DeMarree et al., 2020) and student's performance was limited and mixed. These authors found that the average correlation between self-esteem and academic performance was relatively low (in the range of 0.21 to 0.26 ). Furthermore, many efforts designed to improving students' self-esteem turned out to be potentially counterproductive (see, Baumeister et al., 2003, for a review). Although speculative, it is possible that when confidence increased via selfesteem or any other confidence-related variable (such as self-affirmation, empowerment, positive emotions, etc.) failed to produce desired positive outcomes in previous research it was due, at least in part, to the presence of negative thoughts (e.g., I am feeling anxious about this test) that were being validated by the confidence induction. As demonstrated in the current studies, increasing feelings of confidence can be detrimental for performance when the thoughts validated are negative.

Just as metacognitive confidence was able to devalue but also enhance performance in the current research, future research should examine whether feelings of confidence can also either increase or decrease other important outcomes such as desirable career choices, or teamwork. Given the uniqueness of separating between thought-content and thoughtvalidity, the present approach has the potential to break new ground in other areas relevant to education.

In closing, we recommend the use of validity-related measures and inductions as being useful tools in any domain in which thoughts can affect performance. As shown, questions about thought confidence are easy for researchers and practitioners to use, and students find them easy to answer. Beyond their ease of use and efficiency, we suggest including confidence measures as a potential moderator of the effects of any other mental constructs. In accord with prior research (Paredes et al., 2020, 2021; Shoots-Reinhard et al., 2015) metacognitive confidence measures, which are relevant with regards to performance in academic settings (Stankov \& Lee, 2008; Stankov et al., 2012), can increase the predictive validity of any mental content, including not only thoughts about exams and self-relevant thoughts, but also any other mental construct potentially examined in future studies. 


\section{Conclusion}

This research finds that performance in academic settings is affected by an interaction between the valence of student's thoughts (primary cognition) and the metacognitive confidence with which those thoughts are held (secondary cognition). Metacognitive processes of validation can apply to any content of primary cognitions, including thoughts about exams and self-relevant thoughts. In particular, this research showed that measuring the spontaneous confidence with which primary cognitions are held can lead to increased predictability of the effects of those cognitions on performance (Study 1). Beyond being measured, metacognitive confidence can also be manipulated to be high or low showing the same pattern of results (Studies 2 and 3). That is, metacognitive thought confidence, whether it is measured or manipulated, can lead to opposite findings on academic performance depending on the valence of the thoughts in a person's mind. Thus, rather than being inherently beneficial, metacognitive confidence can increase performance in some cases (e.g., when people are thinking about positive performance-relevant thoughts), but decrease performance in other cases (e.g., for negative thoughts).

Funding Research was supported by the Ministerio de Ciencia e Innovación y Universidades, Gobierno de España (ES) [PSI2017-83303-C2-1-P] Grant to Pablo Briñol. Open Access funding provided thanks to the CRUE-CSIC agreement with Springer Nature.

Data Availability Data for all studies can be found at https://osf.io/bzymh.

Open Access This article is licensed under a Creative Commons Attribution 4.0 International License, which permits use, sharing, adaptation, distribution and reproduction in any medium or format, as long as you give appropriate credit to the original author(s) and the source, provide a link to the Creative Commons licence, and indicate if changes were made. The images or other third party material in this article are included in the article's Creative Commons licence, unless indicated otherwise in a credit line to the material. If material is not included in the article's Creative Commons licence and your intended use is not permitted by statutory regulation or exceeds the permitted use, you will need to obtain permission directly from the copyright holder. To view a copy of this licence, visit http://creativecommons.org/licenses/by/4.0/.

\section{References}

Ais, J., Zylberberg, A., Barttfeld, P., \& Sigman, M. (2016). Individual consistency in the accuracy and distribution of confidence judgments. Cognition, 146(1), 377-386. https://doi.org/10.1016/j.cogni tion.2015.10.006

Au, R. C. P., Watkins, D., Hattie, J., \& Alexander, P. (2009). Reformulating the depression model of learned hopelessness for academic outcomes. Educational Research Review, 4(2), 103-117. https://doi.org/10.1016/j.edurev.2009.04.001

Bandura, A. (1977). Self-efficacy: Toward a unifying theory of behavioral change. Psychological Review, 84(2), 191-215. https://doi.org/10.1037/0033-295x.84.2.191

Bandura, A. (1986). The explanatory and predictive scope of self-efficacy theory. Journal of Social and Clinical Psychology, 4(3), 359-373. https://doi.org/10.1521/jscp.1986.4.3.359

Bandura, A. (1989). Regulation of cognitive processes through perceived self-efficacy. Developmental Psychology, 25(5), 729-735. https://doi.org/10.1037/0012-1649.25.5.729

Baumeister, R., Campbell, J., Krueger, J., \& Vohs, K. (2003). Does high self-esteem cause better performance, interpersonal success, happiness, or healthier lifestyles? Psychological Science in the Public Interest, 4(1), 1-44. https://doi.org/10.1111/1529-1006.01431 
Bernstein, A., Hadash, Y., Lichtash, Y., Tanay, G., Shepherd, K., \& Fresco, D. (2015). Decentering and related constructs. Perspectives on Psychological Science, 10(5), 599-617. https://doi.org/10. $1177 / 1745691615594577$

Brewer, W. F., \& Sampaio, C. (2006). Processes leading to confidence and accuracy in sentence recognition: A metamemory approach. Memory, 14(5), 540-552. https://doi.org/10.1080/0965821060 0590302

Brown, A. L. (1987). Executive control, self-regulation, and other more mysterious mechanisms. In F. E. Weinert \& R. H. Kluwe (Eds.), Metacognition, motivation and understanding (pp. 65-116). Lawrence Erlbaum.

Briñol, P., \& DeMarree, K. G. (2012). Social metacognition. Psychology Press. https://doi.org/10.4324/ 9780203865989

Briñol, P., Gascó, M., Petty, R. E., \& Horcajo, J. (2013). Treating thoughts as material objects can increase or decrease their impact on evaluation. Psychological Science, 24(1), 41-47. https://doi.org/10.1177/ 0956797612449176

Briñol, P., McCaslin, M. J., \& Petty, R. E. (2012). Self-generated persuasion: Effects of the target and direction of arguments. Journal of Personality and Social Psychology, 102(5), 925-940. https://doi.org/10. $1037 / \mathrm{a} 0027231$

Briñol, P., \& Petty, R. E. (2009a). Source factors in persuasion: A self-validation approach. European Review of Social Psychology, 20(1), 49-96. https://doi.org/10.1080/10463280802643640

Briñol, P., \& Petty, R. E. (2009b). Persuasion: Insights from the self-validation hypothesis. In M. P. Zanna (Ed.), Advances in experimental social psychology, 41 (pp. 69-118). Academic Press.

Briñol, P., \& Petty, R. E. (2003). Overt head movements and persuasion: A self-validation analysis. Journal of Personality and Social Psychology, 84(6), 1123-1139. https://doi.org/10.1037/0022-3514.84.6. 1123

Briñol, P., Petty, R. E., \& Tormala, Z. L. (2006). The malleable meaning of subjective ease. Psychological Science, 17(3), 200-206. https://doi.org/10.1111/j.1467-9280.2006.01686.x

Briñol, P., Petty, R. E., Valle, C., Rucker, D. D., \& Becerra, A. (2007). The effects of message recipients' power before and after persuasion: A self-validation analysis. Journal of Personality and Social Psychology, 93(6), 1040-1053. https://doi.org/10.1037/0022-3514.93.6.1040

Briñol, P., Petty, R. E., \& Wagner, B. (2009). Body postures effects on self-evaluation: A self-validation approach. European Journal of Social Psychology, 39(6), 1053-1064. https://doi.org/10.1002/ ejsp.607

Burgmer, P., \& Englich, B. (2012). Bullseye! How power improves motor performance. Social Psychological and Personality Science, 4(2), 224-232. https://doi.org/10.13007/375

Callender, A., Franco-Watkins, A., \& Roberts, A. (2016). Improving metacognition in the classroom through instruction, training, and feedback. Metacognition and Learning, 11(2), 215-235. https:// doi.org/10.1007/s11409-015-9142-6

Caraway, K., Tucker, C., Reinke, W., \& Hall, C. (2003). Self-efficacy, goal orientation, and fear of failure as predictors of school engagement in high school students. Psychology in the Schools, 40(4), 417-427. https://doi.org/10.1002/pits.10092

Cohen, J., \& Cohen, P. (1983). Applied multiple regression/correlation analysis for the behavior sciences (2nd ed.). Erlbaum.

Costermans, J., Lories, G., \& Ansay, C. (1992). Confidence level and feeling of knowing in question answering: The weight of inferential processes. Journal of Experimental Psychology: Learning, Memory, and Cognition, 18(1), 142-150. https://doi.org/10.1037/0278-7393.18.1.142

Croizet, J. C., \& Claire, T. (1998). Extending the concept of stereotype threat to social class: The intellectual underperformance of students from low socioeconomic backgrounds. Personality and Social Psychology Bulletin, 24(6), 588-594. https://doi.org/10.1177/0146167298246003

Davis, R., \& Nolen-Hoeksema, N. (2000). Cognitive inflexibility among ruminators and non-ruminators. Cognitive Therapy and Research, 24(6), 699-711. https://doi.org/10.1023/A:1005591412406

De Castella, K., Byrne, D., \& Covington, M. (2013). Unmotivated or motivated to fail? A cross-cultural study of achievement motivation, fear of failure, and student disengagement. Journal of Educational Psychology, 105(3), 861-880. https://doi.org/10.1037/a0032464

DeCaro, M. S., Rotar, K. E., Kendra, M. S., \& Beilock, S. L. (2010). Diagnosing and alleviating the impact of performance pressure on mathematical problem solving. The Quarterly Journal of Experimental Psychology, 63(8), 1619-1630. https://doi.org/10.1080/17470210903474286

DeCelles, K., DeRue, D., Margolis, J., \& Ceranic, T. L. (2012). Does power corrupt or enable? When and why power facilitates self-interested behavior. The Journal of Applied Psychology, 97(3), 681-689. https://doi.org/10.1037/a0026811 
DeMarree, K. G., Briñol, P., \& Petty, R. E. (2014). The effects of power on prosocial outcomes: A selfvalidation analysis. Journal of Economic Psychology, 41, 20-30. https://doi.org/10.1016/j.joep. 2012.07.005

DeMarree, K. G., Petty, R. E., Briñol, P., \& Xia, J. (2020). Documenting individual differences in the propensity to hold attitudes with certainty. Journal of Personality and Social Psychology, 119, 1239-1265. https://doi.org/10.1037/pspa0000241

Dunlosky, J., \& Metcalfe, J. (2009). Metacognition. Sage.

Durso, G. R. O., Briñol, P., \& Petty, R. E. (2016). From power to inaction: Ambivalence gives pause to the powerful. Psychological Science, 27(12), 1660-1666. https://doi.org/10.1177/0956797616 669947

Educational Testing Service. (1999). Practicing to take the general test. Princeton.

Efklides, A. (2011). Interactions of metacognition with motivation and affect in self- regulated learning: The MASRL model. Educational Psychologist, 46, 6-25. https://doi.org/10.1080/00461520.2011.538645

Elliot, A. J., McGregor, H. A., \& Gable, S. (1999). Achievement goals, study strategies, and exam performance: A mediational analysis. Journal of Educational Psychology, 91(3), 549-563. https://doi.org/ 10.1037/0022-0663.91.3.549

Faul, F., Erdfelder, E., Lang, A. G., \& Buchner, A. (2007). G*Power 3: A flexible statistical power analysis program for the social, behavioral, and biomedical sciences. Behavior Research Methods, 39(2), 175-191. https://doi.org/10.3758/bf03193146

Finn, B. (2008). Framing effects on metacognitive monitoring and control. Memory \& Cognition, 36(4), 813-821. https://doi.org/10.3758/mc.36.4.813

Flavell, J. H., Friedrichs, A. G., \& Hoyt, J. D. (1970). Developmental changes in memorization processes. Cognitive Psychology, 1(4), 324-340. https://doi.org/10.1016/0010-0285(70)90019-8

Fleming, S. M., \& Daw, N. D. (2017). Self-evaluation of decision-making: A general Bayesian framework for metacognitive computation. Psychological Review, 124(1), 91-114. https://doi.org/10. $1037 /$ rev0000045

Fleming, S. M., \& Lau, H. C. (2014). How to measure metacognition. Frontiers in Human Neuroscience, 8. https://doi.org/10.3389/fnhum.2014.00443

Fleming, S. M., Weil, R. S., Nagy, Z., Dolan, R. J., \& Rees, G. (2010). Relating introspective accuracy to individual differences in brain structure. Science, 329(5998), 1541-1543. https://doi.org/10. 1126/science. 1191883

Gascó, M., Briñol, P., Santos, D., Petty, R. E., \& Horcajo, J. (2018). Where did this thought come from? A self-validation analysis of the perceived origin of thoughts. Personality and Social Psychology Bulletin, 44(11), 1615-1628. https://doi.org/10.1177/0146167218775696

Gilman, R., Dooley, J., \& Florell, D. (2006). Relative levels of hope and their relationship with academic and psychological indicators among adolescents. Journal of Social and Clinical Psychology, 25(2), 166-178. https://doi.org/10.1521/jscp.2006.25.2.166

Goupil, L., \& Kouider, S. (2019). Developing a reflective mind: From core metacognition to explicit self-reflection. Current Directions in Psychological Science, 28(4), 403-408. https://doi.org/10. $1177 / 0963721419848672$

Graft, L. K. M., Mayer, S., \& Landwehr, J. R. (2017). Measuring processing fluency: One versus five items. Journal of Consumer Psychology, 28(3), 393-411.

Grass, J., Strobel, A., \& Strobel, A. (2017). Cognitive investments in academic success: The role of need for cognition at university. Frontiers in Psychology, 8. https://doi.org/10.3389/fpsyg.2017.00790

Hacker, D., Bol, L., Horgan, D. D., \& Rakow, E. (2000). Test Prediction and Performance in a Classroom Context. Journal of Educational Psychology, 92(1), 160-170. https://doi.org/10.1037/00220663.92.1.160

Hacker, D. J., Dunlosky, J., \& Graesser, A. C. (2009). Handbook of metacognition in education. Routledge. https://doi.org/10.4324/9780203876428

Hansford, B. C., \& Hattie, J. A. (1982). The relationship between self and achievement/performance measures. Review of Educational Research, 52(1), 123-142. https://doi.org/10.3102/00346543052001123

Hatzigeorgiadis, A., Zourbanos, N., Galanis, E., \& Theodorakis, Y. (2011). Self-talk and sports performance. Perspectives on Psychological Science, 6(4), 348-356. https://doi.org/10.1177/17456 91611413136

Hermann, A. D., Leonardelli, G. J., \& Arkin, R. M. (2002). Self-doubt and self-esteem: A threat from within. Personality and Social Psychology Bulletin, 28(3), 395-408. https://doi.org/10.1177/01461 67202286010

Hertwig, R., \& Grüne-Yanoff, T. (2017). Nudging and boosting: Steering or empowering good decisions. Perspectives on Psychological Science, 12(6), 973-986. https://doi.org/10.1177/1745691617 702496 
Hirsh, J. B., Galinski, A. D., \& Zhong, C. B. (2011). Drunk, powerful, and in the dark: How general processes of disinhibition produce both prosocial and antisocial behavior. Perspectives on Psychological Science, 6(5), 415-427. https://doi.org/10.1177/1745691611416992

Horcajo, J., Paredes, B., Higuero, G., Briñol, P., \& Petty, R. E. (2019). The effects of overt head movements on physical performance after positive versus negative self-talk. Journal of Sport and Exercise Psychology, 41(1), 36-45. https://doi.org/10.1123/jsep.2018-0208

Horcajo, J., Santos, D., Guyer, J. J., \& Mateos, R. (2020). A meta-cognitive approach to doping in sports: The effects of thought validation on attitudes related to doping. Journal of Sports Sciences, 38(19), 2242-2252. https://doi.org/10.1080/02640414.2020.1776930

Hunsley, J. (1985). Test anxiety, academic performance, and cognitive appraisals. Journal of Educational Psychology, 77(6), 678-682. https://doi.org/10.1037/0022-0663.77.6.678

Jamieson, J. P., \& Harkins, S. G. (2009). The effect of stereotype threat on the solving of quantitative GRE problems: A mere effort interpretation. Personality and Social Psychology Bulletin, 35(10), 1301-1314. https://doi.org/10.1177/0146167209335165

Jamieson, J. P., Mendes, W. B., Blackstock, E., \& Schmader, T. (2010). Turning the knots in your stomach into bows: Reappraising arousal improves performance on the GRE. Journal of Experimental Social Psychology, 46(1), 208-212. https://doi.org/10.1016/j.jesp.2009.08.015

Killeya, L. A., \& Johnson, B. T. (1998). Experimental induction of biased systematic processing: The directed-thought technique. Personality and Social Psychology Bulletin, 24(1), 17-33. https://doi. org/10.1177/0146167298241002

Koriat, A. (2011). Subjective confidence in perceptual judgments: A test of the self-consistency model. Journal of Experimental Psychology: General, 140, 117-139. https://doi.org/10.1037/a0022171

Koriat, A. (2019). Confidence judgments: The monitoring of object-level and same level performance. Metacognition and Learning, 14, 463-478. https://doi.org/10.1007/s11409-019-09195-7

Körner, R., Köhler, H., \& Schütz, A. (2020). Powerful and confident children through expansive body postures? A preregistered study of fourth graders. School Psychology International, 41(4), 315330. https://doi.org/10.1177/0143034320912306

Lammers, J., Dubois, D., Rucker, D. D., \& Galinsky, A. D. (2013). Power gets the job: Priming power improves interview outcomes. Journal of Experimental Social Psychology, 49(4), 776-779. https://doi.org/10.1016/j.jesp.2013.02.008

Lange, A., Richard, R., Gest, D. V., \& M., \& Lodder, L. . (1998). The effects of positive self-instruction: A controlled trial. Cognitive Therapy and Research, 22(3), 225-236. https://doi.org/10.1023/A:10187 40725281

Lee, S., \& Schwarz, N. (2021). Grounded procedures: A proximate mechanism for the psychology of cleansing and other physical actions. Behavioral and Brain Sciences, 44, E1. https://doi.org/10.1017/s0140 $525 \times 20000308$

Maclellan, E. (2013). How might teachers enable learner self-confidence? A Review Study. Educational Review, 66(1), 59-74. https://doi.org/10.1080/00131911.2013.768601

Martens, A., Johns, M., Greenberg, J., \& Schimel, J. (2006). Combating stereotype threat: The effect of selfaffirmation on women's intellectual performance. Journal of Experimental Social Psychology, 42(2), 236-243. https://doi.org/10.1016/j.jesp.2005.04.010

Martin, A. J. (2012). Fear of failure in learning. In N. M. Seel (Ed.), Encyclopedia of the sciences of learning. Springer. https://doi.org/10.1007/978-1-4419-1428-6_266

Mayer, R., \& Alexander, P. (2011). Handbook of research on learning and instruction: Educational psychology handbook series. Routledge. https://doi.org/10.4324/9780203839089

Merlo, K. L., Shaughnessy, S. P., \& Weiss, H. M. (2018). Affective influences on within-person changes in work performance as mediated by attentional focus. European Journal of Work and Organizational Psychology, 27, 126-139. https://doi.org/10.1080/1359432X.2017.1417258

McGuire, W. J., \& McGuire, C. V. (1996). Enhancing self-esteem by directed-thinking tasks: Cognitive and affective positivity asymmetries. Journal of Personality and Social Psychology, 70(6), 1117-1125. https://doi.org/10.1037/0022-3514.70.6.1117

Metcalfe, J. (2009). Metacognitive judgments and control of study. Current Directions in Psychological Science, 18(3), 159-163. https://doi.org/10.1111/j.1467-8721.2009.01628.x

Miyake, A., Kost-Smith, L., Finkelstein, N., Pollock, S., Cohen, G., \& Ito, T. (2010). Reducing the gender achievement gap in college science: A classroom study of values affirmation. Science, 330(6008), 1234-1237. https://doi.org/10.1126/science.1195996

Mrazek, M. D., Franklin, M. S., Phillips, D. T., Baird, B., \& Schooler, J. W. (2013). Mindfulness training improves working memory capacity and GRE performance while reducing mind wandering. Psychological Science, 24(5), 776-781. https://doi.org/10.1177/0956797612459659 
Muller, D., Charles, M. J., \& Yzerbyt, V. Y. (2005). When moderation is mediated and mediation is moderated. Journal of Personality and Social Psychology, 89(6), 852-863. https://doi.org/10.1037/00223514.89.6.852

Nietfeld, J., Cao, L., \& Osborne, J. (2005). Metacognitive monitoring accuracy and student performance in the postsecondary classroom. Journal of Experimental Education, 74(1), 7-28. https://psycnet.apa. org/record/2005-13383-001

Paredes, B., Guyer, J., Briñol, P., \& Petty, R. E. (2019). Subtle priming of subtraction vs. addition: A spillover effect of math. International Journal of Social Psychology, 34(3), 590-622. https://doi.org/10. 1080/02134748.2019.1649890

Paredes, B., Santos, D., Briñol, P., Gómez, Á., \& Petty, R. E. (2020). The role of meta-cognitive certainty on the relationship between identity fusion and endorsement of extreme pro-group behavior. Self and Identity, 19(7), 804-824. https://doi.org/10.1080/15298868.2019.1681498

Paredes, B., Briñol, P., Cuesta, U., Martinez, L., Petty, R. E., \& Moreno, L. (2021). The role of metacognitive certainty on the relationship between a porn scale and subsequent pornography consumption. Psicothema, 33(3), 442-448.

Peper, E., Harvey, R., Mason, L., \& Lin, I. M. (2018). Do better in math: How your body posture may change stereotype threat response. Neuroregulation, 5, 67-74. https://doi.org/10.15540/nr.5.3.105

Petty, R. E., \& Cacioppo, J. T. (1979). Issue-involvement can increase or decrease persuasion by enhancing message-relevant cognitive responses. Journal of Personality and Social Psychology, 37(10), 19151926. https://doi.org/10.1037/0022-3514.37.10.1915

Petty, R. E., \& Cacioppo, J. (1986). Communication and persuasion: Central and peripheral routes to attitude change. Springer-Verlag.

Petty, R. E., Briñol, P., \& Tormala, Z. L. (2002). Thought confidence as a determinant of persuasion: The self-validation hypothesis. Journal of Personality and Social Psychology, 82(5), 722-741. https://doi. org/10.1037/0022-3514.82.5.722

Petty, R. E., Briñol, P., Tormala, Z. L., \& Wegener, D. T. (2007). The role of meta-cognition in social judgment. In A. W. Kruglanski \& E. T. Higgins (Eds.), Social psychology: Handbook of basic principles (2nd ed., pp. 254-284). Guilford Press.

Pleskac, T. J., \& Busemeyer, J. R. (2010). Two-stage dynamic signal detection: A theory of choice, decision time, and confidence. Psychological Review, 117(3), 864-901. https://doi.org/10.1037/a0019737

Preacher, K. J., \& Hayes, A. F. (2004). SPSS and SAS procedures for estimating indirect effects in simple mediation models. Behavior Research Methods, Instruments \& Computers, 36(4), 717-731. https:// doi.org/10.3758/BF03206553

Preckel, F., Holling, H., \& Vock, M. (2006). Academic underachievement: Relationship with cognitive motivation, achievement motivation, and conscientiousness. Psychology in the Schools, 43(3), 401411. https://doi.org/10.1002/pits.20154

Rawson, K. A., \& Dunlosky, J. (2007). Improving students' self-evaluation of learning for key concepts in textbook materials. European Journal of Cognitive Psychology, 19(4-5), 559-579. https://doi.org/10. 1080/09541440701326022

Requero, B., Santos, D., Paredes, B., Briñol, P., \& Petty, R. E. (2020). Attitudes toward hiring people with disabilities: A meta-cognitive approach to persuasion. Journal of Applied Social Psychology, 50(5), 276-288. https://doi.org/10.1111/jasp.12658

Roebers, C. M., Schmid, C., \& Roderer, T. (2009). Metacognitive monitoring and control processes involved in primary school children's test performance. British Journal of Educational Psychology, 79(4), 749-767. https://doi.org/10.1348/978185409x429842

Rucker, D. D., Briñol, P., \& Petty, R. E. (2011). Metacognition: Methods to assess primary versus secondary cognition. In K. C. Klauer, A. Voss, \& C. Stahl (Eds.), Cognitive methods in social psychology (pp. 236-264). Guilford Press.

Salancik, G. R., \& Conway, M. (1975). Attitude inferences from salient and relevant cognitive content about behavior. Journal of Personality and Social Psychology, 32(5), 829-840. https://doi.org/10.1037/ 0022-3514.32.5.829

Santos, D., Briñol, P., Petty, R. E., Gascó, M., Gandarillas, B., \& Horcajo, J. (2019). Separating thoughts from the self by selling them to others: The moderating role of self-esteem. International Journal of Social Psychology, 34(3), 506-534. https://doi.org/10.1080/02134748.2019.1649891

Schraw, G., \& Dennison, R. S. (1994). Assessing metacognitive awareness. Contemporary Educational Psychology, 19(4), 460-475. https://doi.org/10.1006/ceps.1994.1033

Schwarzer, R., \& Jerusalem, M. (1995). Generalized self-efficacy scale. In J. Weinman, S. Wright, \& M. Johnston (Eds.), Measures in health psychology: A user's portfolio. Causal and control beliefs (pp. 35-37). Nfer-Nelson. 
Seligman, M. (2018). PERMA and the building blocks of well-being. Journal of Positive Psychology, 13(4), 333-335. https://doi.org/10.1080/17439760.2018.1437466

Shoots-Reinhard, B., Petty, R. E., DeMarree, K. G., \& Rucker, D. D. (2015). Personality certainty and politics: Increasing the predictive utility of individual difference inventories. Political Psychology, 36(4), 415-430. https://doi.org/10.1111/pops.12104

Shrout, P. E., \& Bolger, N. (2002). Mediation in experimental and nonexperimental studies: New procedures and recommendations. Psychological Methods, 7(4), 422-445. https://doi.org/10.1037/1082-989X.7. 4.422

Snyder, C. R., Shorey, H. S., Cheavens, J., Pulvers, K. M., Adams, V. H. I. I. I., \& Wiklund, C. (2002). Hope and academic success in college. Journal of Educational Psychology, 94(4), 820-826. https://doi.org/ $10.1037 / 0022-0663.94 .4 .820$

Stankov, L., \& Lee, J. (2008). Confidence and cognitive test performance. Journal of Educational Psychology, 100(4), 961-976. https://doi.org/10.1037/a0012546

Stankov, L., Lee, J., Luo, W., \& Hogan, D. (2012). Confidence: A better predictor of academic achievement than self-efficacy, self-concept and anxiety? Learning and Individual Differences, 22(6), 747-758. https://doi.org/10.1016/j.lindif.2012.05.013

Strobel, A., Behnke, A., Gärtner, A., \& Strobel, A. (2019). The interplay of intelligence and need for cognition in predicting school grades: A retrospective study. Personality and Individual Differences, 144, 147-152. https://doi.org/10.1016/j.paid.2019.02.041

Taylor, S. E., Lerner, J. S., Sherman, D. K., Sage, R. M., \& McDowell, N. K. (2003). Are self-enhancing cognitions associated with healthy or unhealthy biological profiles? Journal of Personality and Social Psychology, 85(4), 605-615. https://doi.org/10.1037/0022-3514.85.4.605

Taylor, V., \& Walton, G. (2011). Stereotype threat undermines academic Learning. Personality and Social Psychology Bulletin, 37(8), 1055-1067. https://doi.org/10.1177/0146167211406506

Tice, D. M. (1992). Self-concept change and self-presentation: The looking glass self is also a magnifying glass. Journal of Personality and Social Psychology, 63(3), 435-451. https://doi.org/10.1037/00223514.63.3.435

Tod, D., Hardy, J., \& Oliver, E. (2011). Effects of self-talk: A Systematic review. Journal of Sport and Exercise Psychology, 33(5), 666-687. https://doi.org/10.1123/jsep.33.5.666

Tormala, Z. L., Petty, R. E., \& Briñol, P. (2002). Ease of retrieval effects in persuasion: A self-validation analysis. Personality and Social Psychology Bulletin, 28(12), 1700-1712. https://doi.org/10.1177/ 014616702237651

Tormala, Z. L., Falces, C., Briñol, P., \& Petty, R. E. (2007). Ease of retrieval effects in social judgment: The role of unrequested cognitions. Journal of Personality and Social Psychology, 93(2), 143-157. https:// doi.org/10.1037/0022-3514.93.2.143

Van Raalte, J. L., Vincent, A., \& Brewer, B. W. (2016). Self-talk: Review and sport-specific model. Psychology of Sport and Exercise, 22, 139-148. https://doi.org/10.1016/j.psychsport.2015.08.004

Veenman, M. V., \& Alexander, P. (2011). Learning to self-monitor and self-regulate. In R. E. Mayer \& P. A. Alexander (Eds.), Handbook of research on learning and instruction (pp. 197-218). Routledge. https://doi.org/10.4324/9780203839089.ch10

Veenman, M., Elshout, J., \& Meijer, J. (1997). The generality vs domain-specificity of metacognitive skills in novice learning across domains. Learning and Instruction, 7(2), 187-209. https://doi.org/10.1016/ s0959-4752(96)00025-4

Vohs, K., Baumeister, R., \& Ciarocco, N. (2005). Self-regulation and self-presentation: Regulatory resource depletion impairs impression management and effortful self-presentation depletes regulatory resources. Journal of Personality and Social Psychology, 88(4), 632-657. https://doi.org/10.1037/ 0022-3514.88.4.632

von Hippel, C., Kalokerinos, E. K., Haanterä, K., \& Zacher, H. (2019). Age-based stereotype threat and work outcomes: Stress appraisals and rumination as mediators. Psychology and Aging, 34(1), 68-84. https://doi.org/10.1037/pag0000308

von Stumm, S., \& Ackerman, P. (2013). Investment and intellect: A review and meta-analysis. Psychological Bulletin, 139(4), 841-869. https://doi.org/10.1037/a0030746

Wang, M. C., Haertel, G. D., \& Walberg, H. J. (1990). What influences learning? A content analysis of review literature. Journal of Educational Research, 84(1), 30-43. https://doi.org/10.1080/00220671. 1990.10885988

Publisher's Note Springer Nature remains neutral with regard to jurisdictional claims in published maps and institutional affiliations. 